\title{
Evaluating The Usability And Accessibility Of LMS "Blackboard" At King Saud University
}

Dr. Uthman T. Alturki, King Saud University, Saudi Arabia

Dr. Ahmed Aldraiweesh, King Saud University, Saudi Arabia

Dr. Kinshuck, Athabaska University, Canada

\begin{abstract}
King Saud University is in the process of adopting and implementing the interactive Blackboard Learning Management Systems (LMSs) with features that allow members of staff and teachers from different faculties to access, upload assignments, send quizzes, download content, and evaluate the academic progress of the members of faculty. However, many faculty members complain about the accessibility and usability of the e-learning software because of the perceptions that the interactive features are not user friendly. Little research has been done to evaluate the accessibility and usability of the e-learning software. The current study was conducted to answer the research questions on the accessibility and usability of the blackboard vista e-learning software and the barriers of user experience when interacting with blackboard. The study was based on the hypothesis that Blackboard LMS is highly accessible and usable by teachers in the King Saud University and a hypothesis that stated otherwise. The elements that were evaluated using questionnaires include the design user interface, navigational features, and ease of use to answer the research questions. The results proved the hypothesis that 'Blackboard LMS is accessible and usable by the teachers from different faculties for the delivery of content in the King Saud University. However, the study recommends that university should customize the e-learning software to the needs of the teachers to offer courses in English and in Arabic to increase and enhance the accessibility and usability of the software.
\end{abstract}

Keywords: LMS; Blackboard; Usability; Accessibility; E-Learning, Education

\section{INTRODUCTION}

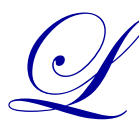
earning management systems (LMSs) have become the main platforms for the delivery of knowledge in most course related activities such as discussions, managing instructional content, making presentations, administering quizzes, and for determining the learning needs of others. However, the LMS e-learning platform, which has become an important tool in modern higher learning institutions, but has not been fully evaluated to determine the suitability of the software for higher learning institutions (Zemsky \& Massy, 2009). Alshwaier, Youssef and Emam (2012) show that LMS Blackboard is a complex environment with the ability to handle different aspects of teaching processes that makes use of different technologies. Several LMS are universal and although institutions have customised the applications to meet the teacher's needs, little research has been done to show how LMS meets the specific needs of the end user (Pearson \& Bohman, 2009). For instance, in Saudi Arabia, the National Centre for E-Learning and Distance Learning (NCEL) has customized some LMS software and produced a local version of LMS called JUSUR and issues it for free to the local universities, with little information on the suitability of the application for the intended use.

A variety of open-source or commercial LMS are available for use, providing institutions of higher Education with a wide range of options and features. For instance, general LMS have useful tools that make it easy to create and manage course content. In addition to that, collaborative learning support systems, institution resources management systems, test-authoring systems and virtual classroom management systems are widely used in modern learning (Meiselwitz \& Sadera, 2008). King Saud University (KSU) has adopted Blackboard Vista, a type of modern LMS 
that provides faculties and teachers with a powerful set of end user-friendly tools in teaching courses. For example, faculty staff have the opportunity to access the course materials anywhere and anytime, allowing teacher to access course content that their faculties keep posting throughout the semester. Moreover, teachers easily access system to send notes, lecture materials, links to important materials, exams and discussion board. However, little research has been done to determine the accessibility and usability of the e-learning software.

\subsection{Problem Statement}

There are many cases of frustrations and disappointments associated with the use of LMS in most institutions because of the nature of the features that allow the teacher and the faculty members of staff to interact with the elearning software and the perceptions of the user such as poor pedagogical guidance of the system (Nielsen, 2005). In terms of their usability, it has been established that LMS have a number of particularities that are not common in other Web based systems. Past research and studies on LMS applications used in higher institutions in Saudi Arabia have only concentrated on determining issues related to technical features and issues (Zaharias, 2004). This means that there is little knowledge on issues related to usability and accessibility of LMS in institutions of higher learning institutions in Saudi Arabia, especially where individual institutions decide to develop and use their own systems. At KSU, buying Blackboard Vista license is arguably an important step towards developing effective learning and delivery of knowledge. However, with little knowledge in usability and accessibility of LMS at King Saud University, there is need to carry out this current research.

\subsection{Research Questions}

1. What are the essential evaluation features of the LMS on-line platform?

2. How does LMS "Blackboard" enable usability and accessibility through navigation and visual aids?

3. What is the effectiveness of using LMS "Blackboard"?

4. Is buying and implementing "Blackboard" Vista at KSU worth it?

5. Is there any statically significant difference between users according to gender or majors?

6. What are the most useful component for faculties

7. What are the common barriers the hinder using LMS "Blackboard"

\subsection{Hypothesis}

H1: The LMS Blackboard e-learning software is highly accessible and usable among the teachers and faculty staff in King Saud University.

H2: LMS Blackboard is not usable and accessible by teachers and faculty staff of King Saud University

The hypotheses were proved using the literature and administration of questionnaires to answer the research questions and verify or refute the claims of the hypothesis.

\section{LITERATURE REVIEW}

\subsection{Issues with LMS Blackboard}

Several studies have shown that LMSs have enhanced the delivery of education in many higher learning institutions, especially in universities and colleges. However, some faculty staff members have revealed that LMS can pose serious accessibility and usability problems for both the teacher and faculty staff members. For example, some forms of LMS tools such as Chat, Discussions and Wikis has proved to be more problematic for the users (Kim \& Seo, 2009).

According to Inversini et al (2006), there is a strong correlation between the effect of LMS's outcomes and the system's usability. Therefore, perceiving LMS from their usability perspective, has been shown that these systems have some specific particularities not common in other Web sites. For instance, an LMS is an out-of-box product, implying that each institution has the opportunity to adopt an already existing system rather than creating a new 
version (Pierotti, 2010). Secondly, each LMS has to be very flexible in order to meet a variety of needs such as teaching and collaborative and learning styles in different institutions (Nielsen, 1992). Thirdly, LMSs are highly customizable offering a wide range of options for configuration the software at different levels (Sherman, 2009). LMSs are also able to capture the audience because instructors have no option than learn to adopt the specific tool adopted by their institutions.

In an attempt to evaluate the usability and accessibility of the existing LMSs, many studies have produced a range of information (Melton, 2004). Inversini et al., (2006) did a comparative study on four different LMSs, comparing between two open source and two commercial LMS. In addition, a study by Kim and Seo (2009) conducted an evaluation of Moodle, dotLRN and Sakai using heuristics evaluation techniques (Kruse, 2010).

All these studies proved that there are several problems associated with the usability and accessibility of LMSs, including the open source and commercial varieties. A study by Al-Khalifa (2008) was conducted at KSU to evaluate the usability of LMS "JUSUR". JUSUR is a type of LMS that was created and adopted by the National Centre for E-learning and Distance Learning (NCEL). Al-Khalifa (2012) used satisfaction surveys, which measured user satisfaction with the LMS with two questionnaires (Meiselwitz \& Sadera, 2008). According to the results, respondents say the system is friendly. However, they are sometimes dissatisfied with the system because it often suffers from functional and technical problems, causing it to fail. Malfunctioning of the e-learning software was one of the most important problems because most users argue that when the system fails and contingency plans do not exist to enable the teacher and faculty members to recover the lost time. The problem is critical especially when teachers offer quizzes on a given timeline (Meiselwitz \& Sadera, 2008).

\subsection{Requirements for Useful Elements}

According to Babu, Singh and Ganesh (2010), the sole purpose of the LMS system is to effectively accomplish instruction. To ensure optimum utilisation of the application, the e-learning platform needs to be customised with different features to support the interaction and delivery of instructions by the teachers and other users. The goals is to solve instructional problems by use of teams, provide a platforms for the teacher and the faculty members to engage in question and answer sessions and to enable on-line simulations and not to simply provide emailing services platform for users to exchange text messages.

Babu, Singh and Ganesh (2010), Dalsgaard (2006), and Foley (2011) agree on the seven aspects of evaluating the LMS Blackboard, which include how to use the e-learning software for instructional management capabilities, teacher and faculty staff interaction capabilities, information guidance features, and institutional demand for the elearning software. In addition, screen design layout and technology are useful features (Meiselwitz \& Sadera, 2008). Technology, screen design, organisational demand, and instructional activities that offer support for e-learning activities are important because they are directly related to instruction. According to Thacker (2012), demand for the software has to be satisfied before the other evaluation criteria are satisfied. In other words, if an institution intending to use LMS has no demand for the product, the system will not have any effect on the users.

Zakaria, Jamal, Bisht and Koppel (2013) agrees that most Blackboard vista releases integrates and provides easy access and usability of the instructional management feature that because it provides the framework for controlling every aspects of the e-learning administration of the faculty members from the registration to the completion of a member. A critical evaluation of Blackboard based on the instructional management component shows that the application is flexible and allows the teacher to interact freely with the users. The key interaction support features include discussion boards, course reports, grade centre, groups, assignment and form assessments, edit mode on/off, course management, tests/surveys/pools, and drag/drop features.

According to Sahasrabudhe and Lockley (2014), the new Blackboard vista includes customised course menus that consist of multiple contents areas that enable the user to find it easy to organise content. The system has a dashboard for showing updates on what is happening and what shall happen in future besides having the ability to accommodate files, images, and multimedia. The software provides accessibility for enabling users to create journals of any private communication between the teacher and the users (Ghoniemy, Fahmy \& Aljahdali, 2010). The teacher has exclusive rights to decide the journals to be read by the rest of the group members. A heuristic 
evaluation of the software by Melton (2004) in the context of instructional management shows that users easily access instructions, management safety, and course management items without problems. The subcategory of user safety includes access authentication, identification, password management, and ability of the disabled to access and manage the learning process from the platform (Lambert, 2013).

The system screens enable the users to interact and easily navigate through the LMS with clarity of direction, unity, consistency, and provide learner control and provide appropriate multimedia. The elements of a screen are configured to offer a good feel for the user and provide enhanced intuitive user access. Those elements such as buttons and links should be easy to interact with when navigating through the application.

\subsection{Features of the LMS Blackboard}

A typical example of the LMS of the Blackboard e-learning tool consists of the following features:

- Blackboard Vista - is the version of Blackboard currently in use at KSU

- Blackboard Learn - The Blackboard Learn provides an e-learning platform mainly geared for teachers to actively engage learners to access their learning materials at any time. The Learning Management System (LMS) enables the teacher to track success by analysing existing records at the end of each assessment period. The system enables the teacher to actively engage the faculty member in a variety of ways. The Blackboard Learn has a comprehensive set of tools for enhancing collaboration for the teacher and the faculty members in their educational needs.

- Blackboard Collaborate - This is a feature that allows the teacher and the faculty communities to actively engage each other and collaborate on learning issues. The feature is important because it provides the teacher with the ability to track the academic progress of users on the mobile phone enabling the teacher to deliver content to the users such as faculty members as shown below.

- Blackboard Connect - This is a feature that allows the teacher to send content and deliver instructions at any time. The feature enables the teacher and the faculty staff members to share information through text messages in real time using a two way text messaging platform.

- Blackboard Analytics - This feature enables the teacher to analyse the performance of the faculty members and provide results to enable the members to make informed decisions on their academic progress.

- Other features include Blackboard engage, Blackboard mobile, and Blackboard pricing for performing different tasks.

\subsection{LMS “Blackboard" Usability Through Navigation and Visual Aids}

A study conducted to determine the usability and accessibility of LMS "Blackboard" through navigation and visual aids showed that the application has different features that enable the user to access content and other services using navigation and visual aids (Guenaga, Burger \& Oliver, 2004). The pull down menu is a key element that is integrated into the application to help the user interact with the e-learning software. The pull down menu provides the user with the ability to select different options from a single drop down menu. However, a critical evaluation of LMS "Blackboard" shows that the application does not fully integrate the primary navigational tool, making it difficult for a user to navigate and access content and other features they need to use at any time (Al-Mouh, AlKhalifa \& Al-Khalifa, 2014).

Goh, Hong and Gunawan (2013) argue that Blackboard provides drop down menus for limited visual affordances. The menu provides the user with the ability to check a list of choices and select an item from the choices without revealing other icons, which remain hidden until they are revealed by the user. It is important to make the crucial opportunities visible to user when using the drop down menus. Sometimes a side bar can be employed to address the problem of pull down menus and a critical evaluation of the LMS "Blackboard" shows that the application employs side bars to enable the user navigate from one page to another without listing the options available under that one menu. In addition, it has been established that learners and instructors with disabilities have difficulties when interacting with the application. The study was based on eight heuristic categories of interactions to determine the 
usability of the application for teachers and faculty members with disabilities. The evaluation criteria consisted of modules of interactions, grade books, and course content among other features that allow the teacher and the faculties to interact on the platform.

\subsection{Content Creation and Accessibility}

Accessibility is not only important for the delivery of content to the faculty members by the teacher, but it is critical for content creation. A study by different authors shows that very little has been done to provide the teacher with the capability to create content without any barriers (Goh, Hong \& Gunawan (2013). The study revealed that the application provided inefficient sequential keyboard access. However, some versions of the application provide industry standard keyboard interactions to navigate throughout the application by moving from one menu to the other. The application provides different keyboard navigations patterns with different web browsers. However, the interactions within the same web browser is the same and consistent. A close evaluation of the application shows that it provides a help menu to guide visitors to the specific point of interest.

\subsection{Usability and Functionality of LMS "Blackboard"}

Usability is an element that allows the user to determine the acceptance of the application for delivering instructional web based content by the teachers using a heuristic evaluation method (Goh, Hong \& Gunawan, 2013).

Among the inherent barriers to usability of the LMS "Blackboard" are the design issues of the on-line application. Design issues deal with the ease of use of the application, the level of interaction that the application provides the users, the ability of the leaner to control certain aspects of the use of the application, and the attention the application offers to the user for fulfilling their the educational multimedia needs (Badawood \& Steenkamp, 2013).

Researchers agree that a good design should enable the user to send and receive interactive materials for their teaching and learning processes. Eye strain, Internet connections, and the low retention abilities of the system are the necessary prerequisites for using passive materials. The e-learning software does not provide interactive features for that purpose (Chang, 1999).

A heuristic evaluation of Blackboard revealed that the application was not properly designed to address the needs of the teacher and the faculties. That is so despite the efforts of the resource developers have shown in the development of the LMS "Blackboard" system. The study revealed that as the development process continues, the application has increased usability problems because of the integration of new web authoring tools and languages. The main usability problem with the application is the general structure and interface design (Badawood \& Steenkamp, 2013). Most of the usability principles include the visibility of system status, consistent organisation and standardisation of the application features, and ability to provide error messages to the users if an error occurs. A critical analysis of Blackboard application shows that the application lacks some of the features in some of the versions used by the university to help in teaching and content delivery using the e-learning software.

\subsection{Statistics of Gender Usage of LMS “Blackboard” in Institutions}

The statistical usage of LMS "Blackboard" was another area investigated to evaluate the usability, accessibility, and acceptance of the application for content and instructions delivery (Ssekakubo, Suleman \& Marsden, 2013). Several authors wanting to determine the suitability of the application in different institutions conducted survey involving King Saud University. King Saud University (KSU) has adopted the use of LMS "Blackboard" as one of the elearning platforms. More studies to determine the acceptance of the perceptions of the application among teachers and faculty members with different demographic profiles and showed that the teacher's characteristics were important in determining the accessibility, acceptance, and usability of the application for e-learning purposes (Melton, 2004). The most outstanding attributes include gender and motivation in the e-learning environment and previous educational experience with the technology or similar technologies with different learning styles. 


\subsubsection{Barriers to Adopting the Blackboard}

The most outstanding barriers that were identified as critical to the accessibility, acceptance, and use of the elearning environment were language barrier for the faculty in the King Saud University (KSU) (Ssekakubo, Suleman \& Marsden, 2013). Most instructions in the university are offered in Arabic and most of the content materials are in English. Most of the resources and instructions in the King Saud University (KSU) follow a rote learning and teacher centric method of instructions and content delivery (Inversini, Botturi \& Triacca, 2006). The approach limits faculty members to use the new task directed e-learning approach widely adopted and used in western universities (Melton, 2004).

Studies conducted to determine the barriers to the accessibility and usability of LMS Blackboard show self-efficacy to be one of the serious limitations. Self-efficacy is a reflection of what the teacher and the faculty staff belief they are able to achieve based on the skills they possess that can contribute to the successful interactive use of the application (Zins, Bauernfeind, Del Missier, Venturini, \& Rumetshofer, 2004). In addition, environmental issues such the learning environment that includes the interaction styles and features of the e-learning software limit the usability of the software for faculty members of staff studying in KSU. Other features that were determined to contribute to the limitations of the usability of the software include educational practises, technical problems, time and pressure, and the anxiety of the learner and the teacher (Black, 2008)

\section{METHODOLOGY}

The proposed study was to evaluate the usability and accessibility of Blackboard at King Saud University, Riyadh. The study will be qualitative research that aims at describing the phenomenon in question "the level of usability and accessibility of Blackboard at KSU". The study was conducted using the questionnaire as a quantitative data gathering tool. The questionnaire tool was identified to be the most appropriate for the study because large amounts of data could be collected in real time, it was easy to quantify the results of the questionnaire, provide high user satisfaction, are familiar to several respondents, easier to administer, and enabled the study to collect and analyse many items with ease (Georgouli, Skalkidis \& Guerreiro, 2008). To ensure the questionnaires were fully answered, the target population were informed and prepared in advance in liaison with the university's management to allow employees to take part of their time off work and participate in the study.

\subsection{Sample Design}

The selection of the sample design was based on the systematics selection from the study population consisting of faculty staff members and teachers from different colleges in KSU. To ensure a fair distribution and representation of the target population, a random sampling strategy was used to select the participants from the entire population (Smith, 2007). The sampling strategy enabled the fairer representation of the respondents because each person legible to participate had an equal chance of being selected to participate in the study. In addition, it was easy and cost effective to select the sample, easy to identify the most suitable sampling frame, and the entire population was fairly represented.

\subsection{Study Area and Population for the Study}

The study conducted in the second semester of the academic year of 2014. The researchers targeted 400 faculty members from different colleges, consisting of three categories: Health Colleges, Humanities Colleges and Science Colleges .The faculty staff members participated by answering the questions on the usability and accessibility of Blackboard. The participants include males and females faculty members.

Faculty staff members who were selected to participate in the study included those familiar with LMS Blackboard elearning software (Sale, Lohfeld, \& Brazil, 2002). The participants were selected during the second semester session of the academic year when they were undergoing training on different courses using Blackboard to execute different tasks such as obtaining course materials, taking and submitting assignments, asking questions, sharing information, completing on-line and real-time exams (quizzes) and checking course announcements. 
The researchers conducted a questionnaire for evaluating the usability and accessibility of Blackboard, the questionnaire consisted of five sections:

- Section 1: General information about the e-learning software

- Section 2: Accessibility of using LMS Blackboard

- Section 3: Usability and functionality of Blackboard

- Section 4: Barriers of using Blackboard

- Section 5: statistical difference of the users of the LMS Blackboard

Therefore, the researcher assessed the number of items using the questionnaire with functionality, design/layout, outcome and accessibility questions. In addition, the researcher used the questionnaire to target user-satisfaction as well as the usefulness of the LMS Blackboard to answer the study questions. Of the total number of respondents who participated, $58.4 \%$ were male and $43.6 \%$ were female.

\subsection{Instruments}

The questionnaire was the data collection instrument, the Likert scale was used to rate the responses on a scale of 1 to 5 as shown below.

1. Strongly disagree

2. Disagree

3. Neither agree nor disagree

4. Agree

5. Strongly agree

\subsection{Reliability Analysis}

The reliability of the results were based on the statistical results used to measure different concepts of the accessibility and use of the LMS Blackboard e-learning software among the teachers and members of faculties of King Saud University. A reliability value above 0.8 shows a high level of reliability of the results. However, when the result is 0.6 , the reliability of the items was still acceptable (Smith, 2007). A Cronbach's alpha was used to test the reliability of the findings from the study. In addition, a sample was collected and subjected to several tests to ensure consistency of the results. To ensure content, criterion, and construct validities, the study was used to generate specific answers to specific research questions. 


\section{FINDINGS AND DISCUSSION}

Table (1) Shows the responses of the respondents on the usability and accessibility of LMS "blackboard" in KSU

Table 1. Usability and accessibility of LMS "blackboard"

\begin{tabular}{l|c|c|c}
\hline \multicolumn{1}{c|}{ General information } & \% participants & \% Blackboard users & 100 \\
\hline Male (17) & 41.46 & 100 & 100 \\
Female (24) & 0.584 & 100 & 100 \\
Health colleges (9) & 0.204 & No (\%) & Reliability \\
Health humanities college (19) & 0.463 & 0.54 & \\
Science colleges (13) & 0.317 & & \\
\hline \multicolumn{1}{c|}{ Item } & Yes (\%) & 0.83 & \\
principles and theory & 0.46 & & \\
\hline Does blackboard have enough & & & \\
functionality for course content & & 0.17 & \\
management & 0.87 & & \\
\hline Are you using different LMS & & & \\
\hline
\end{tabular}

Statistical software was used to calculate reliability as shown in the table (2).

Table 2. Reliability of the findings

\begin{tabular}{|c|c|c|c|c|}
\hline Variables & Items & CITC & $\begin{array}{c}\text { Cronbach's } \\
\text { Alpha removed }\end{array}$ & Cronbach \\
\hline $\begin{array}{l}\text { Usability and functionality of } \\
\text { blackboard items }\end{array}$ & $\begin{array}{l}1 \\
2 \\
3 \\
4 \\
5\end{array}$ & $\begin{array}{l}0.667 \\
0.604 \\
0.619 \\
0.662 \\
0.637 \\
\end{array}$ & $\begin{array}{l}0.698 \\
0.669 \\
0.854 \\
0.628 \\
0.650 \\
\end{array}$ & 0.674 \\
\hline Barriers of using Blackboard & $\begin{array}{c}6 \\
7 \\
8 \\
9 \\
10 \\
11 \\
12 \\
13 \\
14 \\
15 \\
\mathrm{~V} 16 \\
\end{array}$ & $\begin{array}{l}0.739 \\
0.666 \\
0.624 \\
0.712 \\
0.670 \\
0.603 \\
0.539 \\
0.691 \\
0.674 \\
0.737 \\
0.597 \\
\end{array}$ & $\begin{array}{l}0.897 \\
0.901 \\
0.903 \\
0.898 \\
0.900 \\
0.904 \\
0.906 \\
0.899 \\
0.900 \\
0.897 \\
0.904 \\
\end{array}$ & 0.897 \\
\hline Accessibility of Using Blackboard & $\begin{array}{l}17 \\
18 \\
19 \\
20 \\
21 \\
22 \\
23 \\
24\end{array}$ & $\begin{array}{l}0.559 \\
0.715 \\
0.512 \\
0.585 \\
0.599 \\
0.545 \\
0.553 \\
0.523\end{array}$ & $\begin{array}{l}0.804 \\
0.778 \\
0.811 \\
0.800 \\
0.798 \\
0.818 \\
0.805 \\
0.820\end{array}$ & 0.625 \\
\hline Satisfaction & $\begin{array}{l}25 \\
26 \\
27 \\
\end{array}$ & $\begin{array}{l}0.705 \\
0.784 \\
0.566\end{array}$ & $\begin{array}{l}0.735 \\
0.641 \\
0.804\end{array}$ & 0.6 \\
\hline Loyalty & $\begin{array}{l}28 \\
29 \\
30 \\
31 \\
\end{array}$ & $\begin{array}{l}0.733 \\
0.566 \\
0.542 \\
0.604 \\
\end{array}$ & $\begin{array}{l}0.671 \\
0.765 \\
0.771 \\
0.747 \\
\end{array}$ & 0.756 \\
\hline
\end{tabular}

Corrected-item total correlation (CITC) is greater than five making the reliability of the research high. 


\subsection{Essential Features}

The faculty staff and the teachers rated Blackboard Connect, Blackboard Analytics, Blackboard Learn, and Blackboard Collaborate based on their level of satisfaction on the ease of use on a scale of 1 to 5 . The responses showed that not all the features are equally useful for the faculty members and the teachers. The results showed a mean rate of 4 and above were assigned the most essential features of Blackboard Connect, Blackboard Learn, Blackboard Collaborate and Blackboard Connect, Blackboard Learn, and Blackboard analytic was assigned the lowest rating.

\subsection{How Blackboard" Enables Usability and Accessibility}

The usability and accessibility elements include the interface design, the interactive use of the interface elements, and the functionality of the navigational elements to access instructional materials. The ability by the members of staff to access and use the software outcomes were evaluated based on the user's responses. Results showed that less than $60 \%$ of the faculty staff uses the on-line e-learning software to connect with other Blackboard users for course content delivery. The results showed that the highest number of teacher and faculty staff members prefer to use the software because it makes it easy and convenient to use Blackboard. The teacher preferred to use Blackboard than to hold face-to-face interactions with the target users. However, all the faculty staff agreed that they have used the course content materials by downloading, uploading, organising, and sharing the course materials with the members of faculty. Of the faculty staff who responded, $73 \%$ of the staff members agreed that they were highly satisfied with the use of the e-learning software because of the ease of use and access. On the other hand, $50 \%$ of the respondents who have used Blackboard agreed that they were satisfied with the software with a 2.7 and 3.67 mean range of responses. The specific areas of satisfaction with the use of the software were ease of use to create content for the learners and any other general content for academic viewing and use.

\subsection{Buying and Implementing "Blackboard" Vista at KSU Worth It}

The ratings on of the economic worth of buying and using the software was highly rated (mean of 4) when compared with face to face interactions for the faulty members and teachers. That showed that acceptance level of the use of the e-learning software was high if the obstacles such as language barriers were removed.

\subsection{Effectiveness of Using The LMS "Blackboard"}

Over $56 \%$ of the respondents agreed that the software had good easiness of use, design, and functionality showing that it was highly interactive, with all the required features. Over $56 \%$ agreed that other items that include web based learning outcomes and reliability were positively rated showing that the faculty members were able to access materials, learning activities, and the ability to correct errors. Outcomes, satisfaction, and ability to learn was over $46 \%$ and $41 \%$ of the respondents were natural. A smaller percentage strongly agreed on the effects of the items. When faculty members and teachers were asked to rate the accessibility and usability of the e-learning Blackboard LMS on a scale of 1 to 5 , the results showed that not all the features were useful to the staff and faculty members. Some of the faculty staff rated the software poorly with a mean of 2.0. A critical examination of those who rated the software poorly did not have previous experience of the use of the software and indicated several difficulty experiences. The new users experienced difficulties software navigation problems, high level of anxiety especially when doing exams, perceived the software to be complex and difficulty to navigate through, using the software was incompatible with the way most of the users were taught in schools, and most were never motivated to use the software for their studies.

Users with previous experience with Blackboard rated all the features between moderate to medium range of usefulness. The members of faculty rated the 'My Grade' feature highly because it provides the users with the navigational capabilities of viewing their grades and journal was the lowest graded feature on the Blackboard elearning software. The faculty staff and teachers were asked to rate the e-learning software on their perceptions on the accessibility and usability on a scale of 1 to 5 . The results showed a mean rating of 4 on the scale. The teachers highly rated the software on the items that enable them to teach and send assignments effectively. In addition, the faculty staff rated the software highly on the accessibility in enabling them to design the course content materials, 
create on-line tests, and analyse the faculty member's grades in real time. In addition, the respondents were asked to rate the software on the interface layout on a scale of 1 to 5 . The results were analysed and showed that the overall layout and appearance of the software interface is user friendly. The interface allows users to easily interact with the system to post information on discussion boards, blogs, to do lists on the dashboard, preview assignments that have been posted by the teachers, to review course materials and newly posted notifications, and to easily access and track grades.

\subsection{Barriers that Hinder Using LMS "Blackboard"}

However, the members of staff negatively rated the software on its usability in accessing tests and quizzes. The highest negatively rates items were knowledge, time, and equipment failure, difficulty of using blackboard network connectivity, inability to cope, workload due to design, release time, tools and software campus support and suitability for course content received above $56 \%$ negative rating. All other items received less than $40 \%$ negative rating. The faculty members negatively rated the software because of the technical difficulties of loading the software, loss of emails, security issues, and crashing systems. On the other hand, the barriers to the use of blackboard showed that teachers and other faculty staff rated the e-learning software poorly because most of them had no prior experience with the software. Those who had prior experience showed significant positive rating of the e-learning software. Those with little or no prior experience identified lack of knowledge, longer time required to $\log$ into the site and start the program, crashing systems, inability to use the on-line instructional materials, slow network connectivity, weak campus support for the program, and difficult in enrolling in blackboard system for online courses.

\subsection{Statically Significant Difference Between Users According to Gender}

The male teachers and faculty members showed a higher rating for the e-leaning software with a mean rate of four and above than female teachers in the same category. However, the female and male teachers and faculty members rated the e-learning software with a mean rate of 3.5, showing a high level of preference for the software.

\section{SUMMARY}

The aim of the study was to evaluate the usability and accessibility of LMS Blackboard e-learning software for use in the King Saud University. The findings show that the adoption and use of the e-learning software is on the increase among different faculties in the King Saud University, reinforcing the need to evaluate the accessibility and use of the software. Different items were evaluated and on average, the results showed that many teachers were in support of the use of Blackboard LMS for their teaching and learning activities respectively. For instance, the $\log$ in feature is easily accessible and allows any user to log into the page to access the services offered on the platform. The password and user-name field are well laid out for the user to enter the required data to access the system. However, a critical review of the log in features showed that the error messages that are generate if the user makes a password or user-name error should be customised by the institution to the specific needs of the teachers. On the other hand, the interface layout is well customized to the needs of the users because it allows them to reorder page elements and save the desired settings according to their needs and experiences if the administrator has not disabled the features. The Drop box, discussion boards, announcements, communication, and group pages were highly rated showing that the faculty members in KSU are comfortable with the accessibility and use of the e-learning software in the acquisition of course content materials. On the other hand, the teachers rated the discussion boards, assignments, Gradebook, course documentation, announcements, drop box, and communication highly.

\section{CONCLUSION}

This study indicated that the teachers agreed that the e-learning software makes it easy to access and use to deliver course content materials, track the performance, and grade the members of faculty appropriately. Both the faculty members of staff and the teachers agreed that the most helpful areas of the e-learning software include ease of access of access of teaching and learning materials, easy file management approaches, real time access to learning materials, and immediate feedback on the on-line quizzes. On the other hand, the study to evaluate the responses on the barriers to the adoption and use of the software for course materials showed that most of those teachers, and 
faculty staff members were those who had little or no prior experience with the software. The results support the hypothesis that the software is easy to access and use.

\section{ACKNOWLEDGEMENTS}

Researchers thank the research centre of College of Education at King Saud University for their support of this research.

\section{AUTHOR BIOGRAPHIES}

Dr. Alturki is an Associate Professor at educational technology department - College of Education - King Saud University in Saudi Arabia. Before that he was as a full time consultant for three years at (NCEL) National center for e-learning and distance learning. He also was as the head of computer department at teachers college for two years. He was the dean and deputy dean for 4 years in (MoE) Ministry of education. Dr. Alturki obtained his PhD from (KSU) Kansas State University in 2004. Email: ualturki@gmail.com

Dr. Aldraiweesh is an Assistant Professor at educational technology department - College of Education - King Saud University in Saudi Arabia. He was as the head of educational technology department at teachers college for two years. was the head of Quality Unit at teachers college for two years before that. Dr. Aldraiweesh is interested in employing educational technology for student with special needs. He am looking forward to find practical solutions to the problems of education through instructional design. Email: dr.aldraiweesh@gmail.com

Dr. Kinshuk holds the NSERC/iCORE/Xerox/Markin Research Chair for Adaptivity and Personalization in Informatics, funded by the Federal government of Canada, Provincial government of Alberta, and by national and international industries. He is also a Full Professor in the School of Computing and Information Systems and Associate Dean of Faculty of Science and Technology, at Athabasca University, Canada. After completing first degree from India, he earned his Masters' degree from Strathclyde University (Glosgow) and PhD from De Montfort University (Leicester), United Kingdom. His work has been dedicated to advancing research on the innovative paradigms, architectures and implementations of online and distance learning systems for individualized and adaptive learning in increasingly global environments. Email: kinshuk1@gmail.com

\section{REFERENCES}

Al-Khalifa, H. (2008). JUSUR: The Saudi learning management system. Retrieved from http://www.google.com/url?sa=t\&rct=j\&q=\&esrc=s\&source=web\&cd=3\&ved=0CDEQFjAC\&url=http $\% 3 \mathrm{~A} \% 2 \mathrm{~F} \% 2 \mathrm{~F}$ www.iiste.org\%2FJournals\%2Findex.php\%2FIKM\%2Farticle\%2Fdownload\%2F10943\%2F11246\&ei=kQ9BVJLXEoj 3OvipgIAH\&usg=AFQjCNHWPukmArDf6BJDFfjMRn32fVbYrw

Al-Khalifa, H. S (2012). A First Step in Evaluating the Usability of JUSUR Learning Management System. Retrieved from http://www.google.com/url?sa=t\&rct=j\&q=\&esrc=s\&source=web\&cd=1\&ved=0CB8QFjAA\&url=http $\% 3 \mathrm{~A} \% 2 \mathrm{~F} \% 2 \mathrm{Fel}$ exforum.hbmeu.ac.ae\%2FProceeding\%2FPDF\%2FFirst $\% 2520$ Step $\% 2520$ in $\% 2520$ Evaluating $\% 2520$ the $\% 2520$ usabilit y\%2520of\%2520JUSUR.pdf\&ei=Ew9BVJOPCMfUOfjkgOAJ\&usg=AFQjCNFq0eNNU8vUbTyjuDtdapURQrP_jw

Al-Mouh, N. A., Al-Khalifa, A. S., \& Al-Khalifa, H. S. (2014). A First Look into MOOCs Accessibility. Computers Helping People with Special Needs, 1(2), 145-152.

Alshwaier, A., Youssef, A., \& Emam, A. (2012). A new Trend for E-learning in KSA using educational clouds. Advanced Computing: An International Journal (ACIJ), 3(1), 81-97.

Babu, R., Singh, R., \& Ganesh, J. (2010). Understanding blind users' Web accessibility and usability problems. AIS Transactions on Human-Computer Interaction, 2(3), 73-94.

Badawood, A., \& Steenkamp, A. (2013). A Systematic Approach to Faculty Development Towards Improved Capability in Tertiary Teaching in a Blended Learning Environment. Information Systems Education Journal, 11(3), 101.

Black, E. L. (2008). Toolkit approach to integrating library resources into the learning management system. The Journal of Academic Librarianship, 34(6), 496-501.

Chang, V. (1999). Evaluating the effectiveness of on-line learning using a new web based learning instrument. Retrieved from http://www.waier.org.au/forums/1999/chang.html

Dalsgaard, C. (2006). Social software: E-learning beyond learning management systems. European Journal of Open, Distance and E-Learning, 2(2), 20-190.

Foley, A. (2011). Exploring the design, development and use of websites through accessibility and usability studies. Journal of 
Educational Multimedia and Hypermedia, 20(4), 361-385.

Georgouli, K., Skalkidis, I., \& Guerreiro, P. (2008). A Framework for Adopting LMS to Introduce e-Learning in a Traditional Course. Educational Technology \& Society, 11(2), 227-240.

Ghoniemy, S., Fahmy, A., \& Aljahdali, S. (2010). A Dedicated Web-Based Learning System. Universal Journal of Computer Science and Engineering Technology, 1(2), 84-92.

Goh, W. W., Hong, J. L., \& Gunawan, W. (2013). Exploring students' perceptions of learning management system: An empirical study based on TAM. Teaching, Assessment and Learning for Engineering (TALE), IEEE International Conference, 1(1), 367-372

Guenaga, M. L., Burger, D., \& Oliver, J. (2004). Accessibility for e-learning Environments, New York: Springer Berlin Heidelberg

Inversini, A., Botturi, L. \& Triacca, L. (2006). Evaluating LMS Usability for Enhanced eLearning Experience. Proceedings of World Conference on Educational Multimedia, Hypermedia and Telecommunications, 1 (1), 595-601.

Kim, S., \& Seo, B. (2009). The Development of e-Learning Platform for Gifted Children Education. Published on International Journal for Educational Media and Technology, 3(1), 39-51.

Kruse, K. (2010). E-Learning and the Neglect of User Interface Design. Retrieved from http://www.elearningguru.com/articles/art4_1.htm

Lambert, R. (2013). A Tale of Two PCs: An Evaluation of Access Platforms for the Blind Utilizing the" Blackboard Learn" Learning Management System. Retrieved from http://www.google.com/url?sa=t\&rct=j\&q=\&esrc=s\&source=web\&cd=1\&ved=0CB8QFjAA\&url=http $\% 3 \mathrm{~A} \% 2 \mathrm{~F} \% 2 \mathrm{Fd}$ igitalscholarship.unlv.edu\%2Fcgi\%2Fviewcontent.cgi\%3Farticle\%3D3004\%26context\%3Dthesesdissertations\&ei=W BJBVM2QNYGZPOHOgNgP\&usg=AFQjCNEYd3lmxabvxTsIRFJmD-Jgelvd_A

Meiselwitz, G., \& Sadera, W. A. (2008). Investigating the Connection between Usability and Learning Outcomes in On-line Learning Environments. MERLOT Journal of On-line Learning and Teaching, 4(2), 145-151.

Melton, J. (2004). The CMS moodle: A heuristic evaluation. JALTCALL2004, Mito, Japan. Retrieved from http://www.google.com/url?sa=t\&rct=j\&q=\&esrc=s\&source=web\&cd=3\&ved=0CC $8 Q F j A C \& u r l=h t t p \% 3 \mathrm{~A} \% 2 \mathrm{~F} \% 2 \mathrm{Fw}$ ww.pu-

kumamoto.ac.jp\%2F jay\%2Fpres\%2F2004\%2Fjaltcall\%2Fmeltonheuristicshandout.pdf\&ei=IxxBVK2PE4XyPOCrgd AL\&usg=AFQjCNFT3xRA6t3jCH4994z28JgtEQkU5A

Nielsen, J. (1992). Finding usability problems through heuristic evaluation. Monterey, CA: Cengage

Nielsen, J. (2005). Heuristic Evaluation. Retrieved from http://www.useit.com/papers/heuristic/

Pearson, P., \& Bohman, P. (2009). Proceedings of World Conference on Educational Multimedia, Hypermedia and Telecommunications 2006. Retrieved from http://www.editlib.org/p/23070.

Pierotti, D. (2010). Heuristic Evaluation - A System Checklist. Retrieved from http://www.stcsig.org/usability/topics/articles/hechecklist.html.

Sahasrabudhe, S., \& Lockley, M. (2014). Understanding Blind User's Accessibility and Usability Problems in the Context of myITlab Simulated Environment. New York: McGraw-Hill.

Sale, J. E., Lohfeld, L. H., \& Brazil, K. (2002). Revisiting the quantitative-qualitative debate: Implications for mixed-methods research. Quality and quantity, 36(1), 43-53.

Sherman, P. (2009). UPA Salary Survey. New York: McGraw-Hill

Smith, J. A. (2007). Qualitative psychology: A practical guide to research methods. New York: Sage.

Ssekakubo, G., Suleman, H., \& Marsden, G. (2013). Designing mobile LMS interfaces: learners' expectations and experiences. Interactive Technology and Smart Education, 10(2), 147-167.

Thacker, C. (2012). Moving beyond Blackboard: Using a Social Network as a Learning Management System. Metropolitan Universities, 23(2), 11-31.

Zaharias, P. (2004). Usability and e-Learning: The road towards integration. ACM eLearn Magazine, 204(6), 223-235.

Zakaria, N., Jamal, A., Bisht, S., \& Koppel, C. (2013). Embedding a Learning Management System Into an Undergraduate Medical Informatics Course in Saudi Arabia: Lessons Learned. Medicine 2.0, 2(2), 13.

Zemsky, R., Massy W.F. (2009). Thwarted Innovation What Happened to e-learning and Why. Retrieved from http://www.thelearningalliance.info/Docs/Jun2004/ThwartedInnovation.pdf

Zins, A. H., Bauernfeind, U., Del Missier, F., Venturini, A., \& Rumetshofer, H. (2004). An experimental usability test for different destination recommender systems. New York: McGraw-Hill. 